\title{
ABNORMAL MOTION PROCESSING AND BINOCULARITY: INFANTILE ESOTROPIA AS A MODEL SYSTEM FOR EFFECTS OF EARLY INTERRUPTIONS OF BINOCULARITY
}

\author{
ANTHONY M. NORCIA \\ San Francisco, California
}

\begin{abstract}
SUMMARY
Infantile esotropia, a common form of strabismus with onset prior to 6 months of age, occurs at a time of rapid visual development. While monocular visual acuity is relatively unaffected in these patients, the majority of them fail to achieve fully normal stereopsis. In addition, these patients show a spectrum of abnormalities in their ocular following responses, visual perception and visual evoked potentials (VEPs) that suggest a failure to develop a normal complement of motion processing mechanisms. While abnormalities of stereopsis have been studied for many years, motion processing in strabismus is a rapidly evolving area of current research. Motion mechanisms are normally binocular and may form a distinct binocular sub-system. This review summarises what is known about sensory and motor abnormalities in infantile esotropia, with special emphasis on recent motion VEP recordings. The monocular motion VEP shows directional biases early in infancy that are consistent with a nasalward/ temporalward response bias. Patients with infantile esotropia maintain their neonatal biases beyond the age at which they normally disappear. The motion VEP biases persist into visual maturity in patients whose strabismus is treated after about 2 years of age. Treatment prior to age 2 can lessen the magnitude of the motion VEP asymmetry and these improvements can be maintained into visual maturity. A recording from the striate cortex of a visually deprived macaque monkey indicates that the motion VEP asymmetry arises early in the visual pathway.
\end{abstract}

Infantile esotropia is a form of constant strabismus that has its onset between birth and 6 months of age. ${ }^{1-3}$ The first 6 months of life are a critical period for the development of binocularity in humans. ${ }^{4.5}$

Correspondence to: A. M. Norcia, Smith-Kettlewell Eye Research Institute, 2232 Webster Street, San Francisco, CA 94115, USA.
Infantile esotropia is thus a particularly potent interruption of normal brain maturation. Acuity is equal, but mildly subnormal in infants with infantile esotropia prior to surgery ${ }^{6.7}$ and up to 5-7 years of age. ${ }^{8}$ Amblyopia is relatively infrequent in these patients, ${ }^{3}$ especially in those who show spontaneous alternation of fixation. The infantile estropia model is thus relatively free of the confounding effects of reduced monocular vision secondary to amblyopia and of the effects on binocularity that might be unique to amblyopia. ${ }^{9}$

\section{MOTOR ABNORMALITIES IN INFANTILE ESOTROPIA}

The strabismus seen in infantile isotropia is frequently a stable, alternating, large angle esotropia. ${ }^{3}$ The strabismus may be associated with defective abduction, excessive adduction, oblique muscle overaction, dissociated vertical deviation and latent nystagmus. These patients also exhibit a number of abnormalities in their ocular following responses that imply the presence of a nasalward-temporalward asymmetry at one or more stages of motion processing.

Monocular optokinetic nystagmus (MOKN) is asymmetric in infantile estropia - the patients show a characteristically weak temporalward slow phase. ${ }^{10-15}$ Fig. 1 shows MOKN recorded from a normal adult (top panels) and from an adult with a history of infantile esotropia (bottom panels). The target was a 1 cycle/degree (c/deg) grating drifting either nasalward or temporalward at $9.4 \mathrm{deg} / \mathrm{s}$. MOKN is vigorous in both directions in the normal observer, but in the patient, nystagmus is vigorous only for the temporal-to-nasal direction in the visual field (i.e. nasalward motion). Pursuit eye movements in patients with infantile esotropia are also asymmetric - these patients fail to track smoothly the temporalward motion of small targets ${ }^{16}$ and pursuit acceleration in the step-ramp task has significantly

Eye (1996) 10, 259-265 C 1996 Royal College of Ophthalmologists 

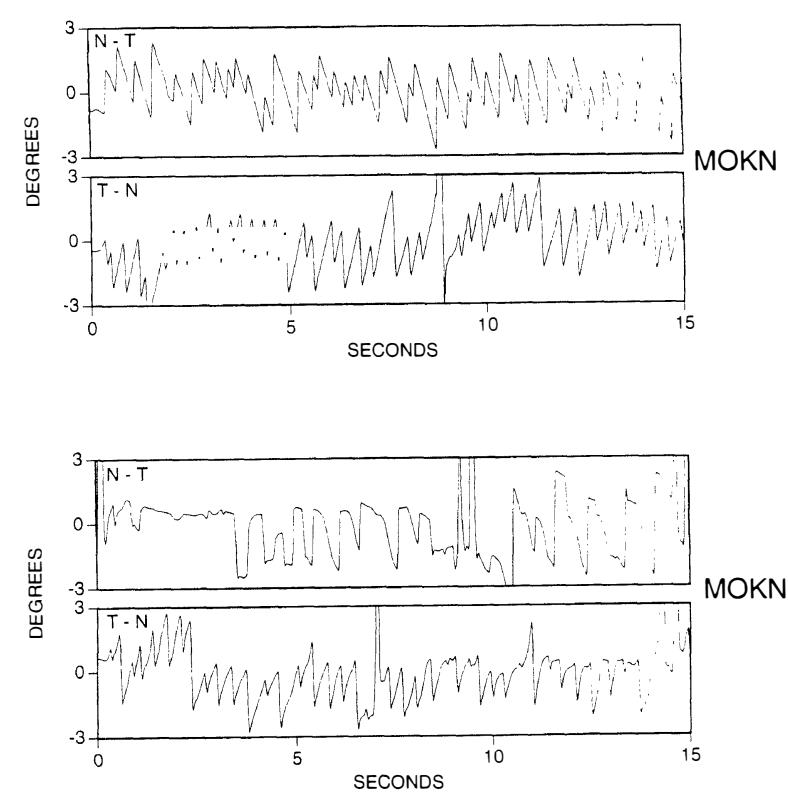

Fig. 1. Upper panels: Monocular OKN records for a normal adult for nasal-to-temporal motion in the visual field (upper trace) and for temporal-to-nasal motion (lower trace). Vigorous MOKN is generating in both directions. Lower panels: $M O K N$ records for an adult with a history of infantile esotropia. MOKN is markedly stronger for the temporal-to-nasal (nasalward) direction than for the nasalto-normal (temporalward) direction. The observers viewed a high-contrast $1 \mathrm{c} / \mathrm{deg}$ grafting drifting at $9.4 \mathrm{deg} / \mathrm{s}$ in a 13 deg $\times 9$ deg field. The eye movements were recorded with an infrared limbus tracker.

higher open-loop gain for nasalward as compared with temporalward motion. ${ }^{9}$

\section{SENSORY PROFILE OF INFANTILE ESOTROPIA}

Reduced Stereopsis

In spite of their relatively normal monocular acuity, patients with a history of infantile esotropia very commonly have reduced stereoacuity.17.18 Fully normal stereopsis at visual maturity is infrequent, ${ }^{18}$ but some of these patients nonetheless do exhibit measurable stereopsis. ${ }^{17}$ Infants with infantile esotropia have been reported to show some evidence of stereopsis prior to surgery and for varying periods after surgery. ${ }^{19-23}$

\section{Motion Asymmetries}

Infantile esotropia patients report that targets moving nasalward appear to be of a higher velocity than temporalward-moving targets with the same objective velocity. ${ }^{9}$ However, two recent reports ${ }^{24,25}$ have found evidence that the perceptual bias is opposite to that found by Tychsen and Lisberger. ${ }^{9}$ The reason for the discrepancy of results is unclear at present, and more work is clearly needed.

Infantile esotropia patients also report that a contrast reversing grating appears to drift nasally. ${ }^{26,27}$ A reversing grating is a directionally ambiguous stimulus which contains components drifting in opposite directions. On the surface, it would appear that the nasalward component of the stimulus is dominant. However, the interpretation of the reversing grating findings in infantile esotropia patients is complicated by the effect latent nystagmus has on the retinal image. Even normal observers will report unidirectional drift when they make smooth tracking eye movements over a reversing pattern. The reported motion in normal observers is in the direction of the eye movement, which would be nasalward in patients with latent nystagmus.

Tychsen and Lisberger ${ }^{9}$ suggested that asymmetries in pursuit eye movements and in perceived velocity imply that analogous asymmetries must be present at the level of visual cortex. Norcia and coworkers ${ }^{28}$ have found evidence for a cortical motion asymmetry in patients with a history of early onset esotropia treated after 2 years of age. They found that monocular oscillatory-motion visual evoked potentials (VEPs) from these patients contained both first $\left(F_{1}\right)$ and second harmonic $\left(F_{2}\right)$ components, while normal, mature responses were dominated by $F_{2}$. Representative spectra from a normal adult, a visually mature infantile esotrope and a normal visually immature infant are shown in Fig. 2. The mature response is dominated by second $\left(F_{2}\right)$ and fourth $\left(F_{4}\right)$ harmonics of the $6 \mathrm{~Hz}$ stimulus frequency. In contrast, the motion responses of both the normal infant and of the visually mature infantile esotrope contain prominent responses at the stimulus fundamental $F_{1}$. The presence of an $F_{1}$ component is consistent with a directional asymmetry of cortical responsiveness. Moreover, the $F_{1}$ components have opposite temporal phase in the two eyes, indicating that the largest response from each eye had resulted from opposite directions of motion. This is illustrated in Fig. 3 which shows motion VEP responses at $F_{1}$ and $F_{2}$ for a normal adult, a normal infant and an adult with a history of infantile esotropia. The data are plotted in polar form, with the length of the vectors indicating the response amplitude and the angle indicating the response phase with respect to the stimulus. Both the infant and infantile esotropia patient have prominent $F_{1}$ responses that are $180 \mathrm{deg}$ out of phase in the two eyes. Unfortunately, the absolute direction of the asymmetry, nasalward or temporalward, cannot be recovered from the $F_{1}$ data, since there is an inherent $180 \mathrm{deg}$ phase ambiguity introduced by the unknown polarity of the response. Kommerrell and co-workers ${ }^{29}$ have replicated Norcia et al.'s results for visually mature infantile esotropia patients. 


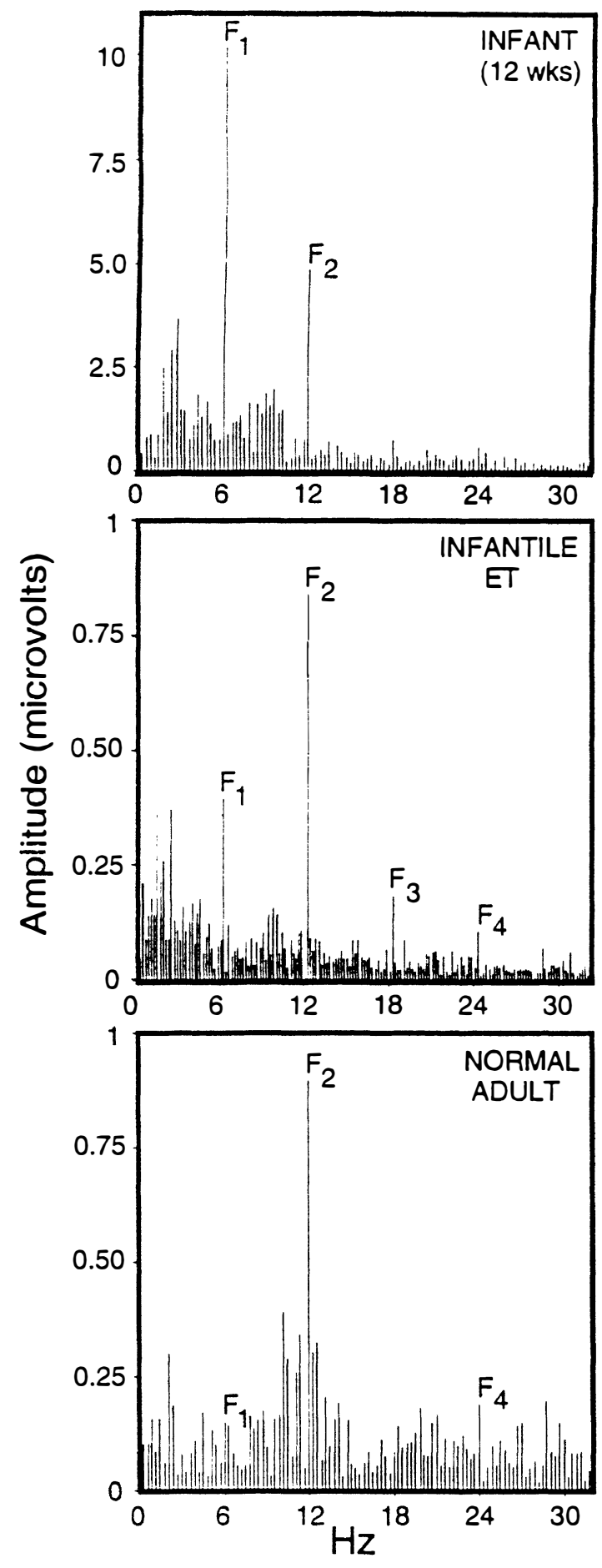

Fig. 2. Representative amplitude spectra for monocular oscillatory-motion VEPs recorded from a normal, visually immature infant (age 12 weeks; top), a visually mature infantile esotropia patient (age 12 years; middle) and a normal adult (bottom). The monocular motion VEP is dominated by $\mathrm{F}_{1}$ and $\mathrm{F}_{2}$ components in the normal infant and in the infantile esotrope. The normal adult response is dominated by the $\mathrm{F}_{2}$ component. Higher harmonic components were present in the older observers, but not in the 12week-old infant. (Reprinted with permission from Norcia et al. ${ }^{37}$ ).

\section{RELATIONSHIP TO NORMAL DEVELOPMENT}

An asymmetric motion VEP is physiological early in normal development. ${ }^{30,31}$ Depending on the spatial and temporal conditions of the test, normal infants achieve a symmetric motion response between 5 months and approximately 2 years of age. ${ }^{30}$ Normal infants also show asymmetric $\mathrm{MOKN}^{32,33}$ and nystagmus is elicited by directionally ambiguous reversing gratings viewed monocularly. ${ }^{34}$ Infantile esotropia blocks the normal developmental progression of the motion VEP and MOKN.

\section{PLASTICITY OF BINOCULAR MOTION MECHANISMS FOLLOWING TREATMENT}

Prior to treatment, infants with infantile esotropia display abnormal levels of motion asymmetry compared with age-matched normal controls. Fig. 4 plots an index of the degree of response asymmetry for normal infants (open circle) and for infants with infantile esotropia (square symbols). The index is the ratio of the $F_{1}$ component amplitude to the sum of the $F_{1}$ and $F_{2}$ amplitudes. The index runs between 0 and 1 , with 0 representing a completely symmetric response and 1 a completely asymmetric response. The average monocular asymmetry index was 0.28 for a group of 26 normal infants 25 weeks of age or older (average 38 weeks). The horizontal dashed
(A)
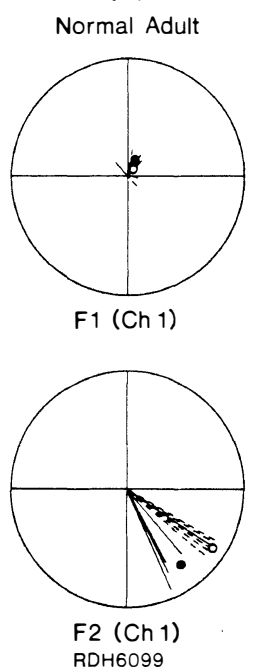

(B)
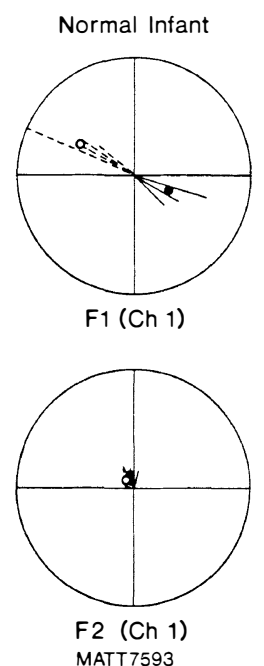

(C)
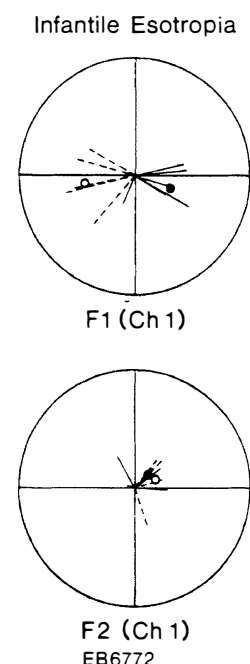

Fig. 3. Motion $V E P$ responses at $\mathrm{F}_{1}$ and $\mathrm{F}_{2}$ for a normal adult, a normal infant and an adult with a history of infantile esotropia. The data are plotted in polar form, with the length of the vectors indicating the response amplitude and the angle indicating the response phase with respect to the stimulus. Both the infant and infantile esotropia patient have prominent $\mathrm{F}_{1}$ responses that are 180 deg out of phase in the two eyes. The $\mathrm{F}_{1}$ response indicates a monocular response asymmetry and the 180 deg phase relationship between the two eyes indicates that opposite directions of motion are dominant in the two eyes. (Reprinted with permission from Norcia et al. ${ }^{28}$ ) 
lines in the figure indicate the $95 \%$ confidence limits for the normal mean. Esotropic infants at an average age of 61 weeks who had not yet received treatment showed levels of VEP motion asymmetry that were clearly abnormal (open square symbol in Fig. 4).

\section{Effects of Occlusion Therapy}

Full-time alternate-day occlusion during the first and second years of life in patients with infantile esotropia has been shown to reduce the degree of motion asymmetry prior to surgery conducted during the second year. ${ }^{31}$ Fig. 4 shows the asymmetry indices from the first and last recordings conducted during occlusion therapy (filled squares). There was a significant decrease in the degree of asymmetry, although the mean value attained after patching was still abnormal. The patients who had had no alternate occlusion therapy up to the time of recording showed a level of response asymmetry that is the same as that seen at the beginning of alternate occlusion therapy (compare the open square and the first filled square in Fig. 4).

Alternate occlusion may act by blocking an active mechanism, such as strabismic suppression, which may help to maintain abnormal levels of motion asymmetry. Westall and Shute ${ }^{15}$ have reported that part-time patching can modify the degree of OKN asymmetry in amblyopic patients. The results of

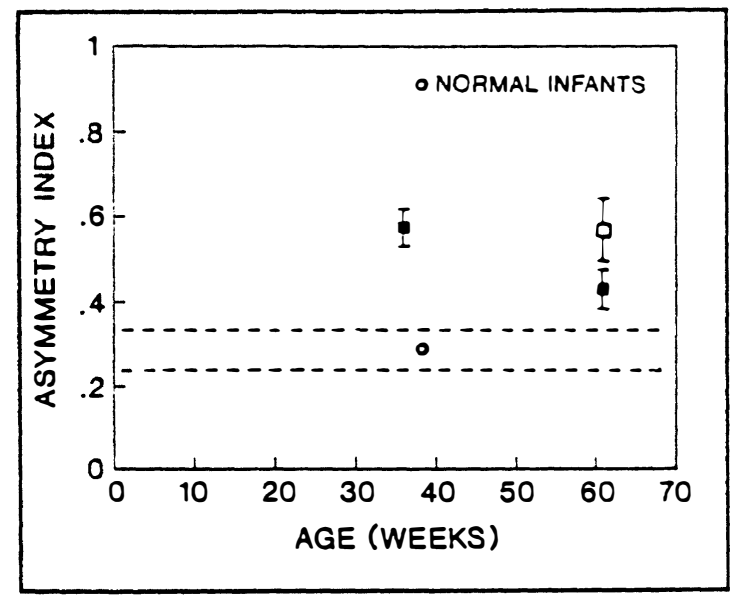

Fig. 4. Group MVEP asymmetry indices for 14 patients before and after alternate day occlusion therapy conducted before surgery for infantile esotropia. The filled squares plot the asymmetry index from the first and last recordings conducted during occlusion therapy. There was a significant decrease in the degree of asymmetry. The open circle shows the average monocular asymmetry index (0.28) for a group of 26 normal infants 25 weeks of age or older (average 38 weeks). The horizontal dashed lines indicate the $95 \%$ confidence limits for the normal mean. The open square symbol indicates the average asymmetry index (0.56) for 6 infantile esotropia patients who had had no alternate occlusion therapy when recorded at an average age of 61 weeks. These patients showed a level of response asymmetry that is the same as that seen at the beginning of alternate occlusion therapy. (Reprinted with permission from Jampolsky et al. ${ }^{31}$ ) occlusion therapy suggest that the mechanisms underlying the various developmental motion asymmetries are experience dependent and, furthermore, that they exhibit plasticity typically associated with developmental sensitive/critical periods. ${ }^{35,36}$

\section{Effects of Surgery}

In a prospective study, the magnitude of the VEP directional bias has been shown to decrease significantly after surgery for infantile esotropia. Fig. 5 shows the decrease in motion asymmetry found in eight infants after surgery for infantile esotropia at an average age at surgery of 1.5 years. After a postoperative follow-up averaging 1.8 years, the patients showed significantly less VEP motion asymmetry than they had demonstrated immediately prior to surgery. Patients who achieved stable, accurate alignment early in life were found to maintain reduced levels of motion VEP asymmetry into visual maturity. Fig. 6 shows normal oscillatory motion VEPs recorded from four infantile esotropia patients 3.9-8.5 years after surgery. Lower levels of motion asymmetry were also seen in a larger group of patients who had been accurately aligned before 2 years of age compared with those who had been aligned later. ${ }^{37}$ Within the late-treatment group, a subgroup of patients who had experienced accurate alignment (less than 10 prism dioptres of residual deviation) after age 2 years fared no better than a subgroup with poorer alignment. The difference between the early and late treatment groups is

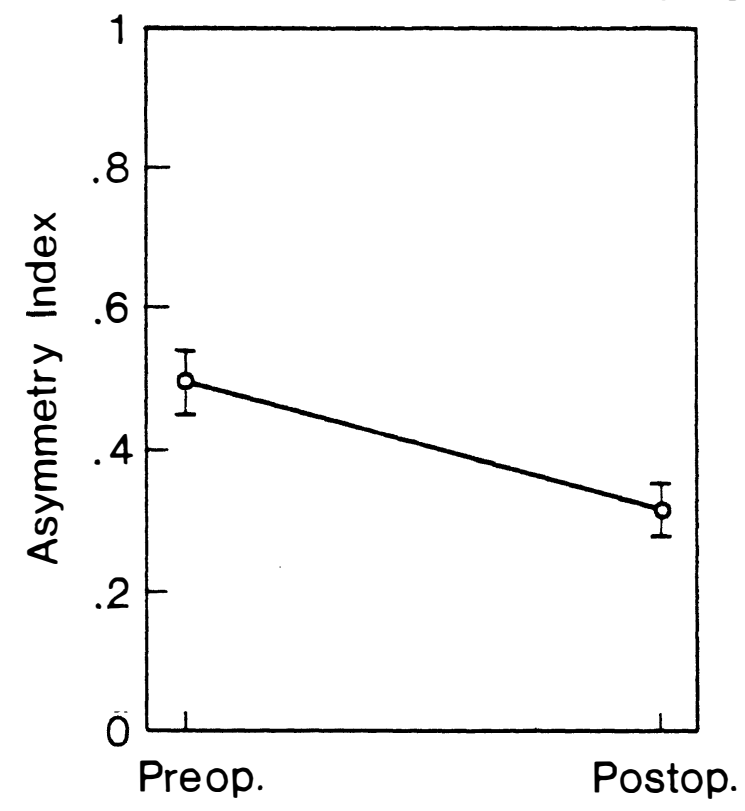

Fig. 5. Motion VEP asymmetry indices of 8 infants before and after surgery for infantile esotropia. The average age of surgery was 1.5 years. After a post-operative follow-up period averaging 1.8 years, the patients showed significantly less VEP motion asymmetry than they had demonstrated immediately prior to surgery. (Reprinted with permission from Norcia et al. ${ }^{37)}$ 
consistent with the existence of a critical period in the development of binocular, direction-selective mechanisms. During this period, accurate alignment may be effective in promoting recovery of a more normal response. Taken together, the patching and surgery effects demonstrate that motion processing mechanisms are plastic within a developmental critical period and that they are dependent on the development of normal binocular interactions.

\section{Effects of Age of Onset of Strabismus}

Unlike normal neonates or patients with early onset strabismus, patients with an onset of esotropia after about age 2 years do not show pronounced nasalward-temporalward direction biases in their motion VEP, ${ }^{38}$ MOKN $^{15}$ or pursuit eye movements. ${ }^{16,39}$ To date, none of the studies of motion asymmetries in late onset esotropia have been prospective. It is thus not clear whether their relative lack of direction biases is the result of never having had them in the first place (e.g. if the strabismus developed after the critical period) or if they lost asymmetries after treatment.

\section{TENTATIVE LOCALISATION OF THE VEP GENERATOR}

VEP directional biases, such as those that are present in normal infants and in patients with disrupted binocularity, may be based on a population of direction-selective cells that have failed to attain normal binocularity. One can infer that the mechanisms tapped by the oscillatory-motion VEP are normally binocular simply because normal binocular interaction in infancy is crucial in determining whether this response is normal. Chandna, Norcia and Peterzell ${ }^{40}$ provided direct experimental evidence that the oscillatory-motion VEP is tapping binocular, direction-selective mechanisms by show- ing that a direction-specific motion aftereffect could be seen in the oscillatory-motion VEP after adaptation to unidirectional drift, and that this aftereffect transferred interocularly. Neurons that are both binocular and direction selective are common as early as area V1 in monkey. ${ }^{41}$ Cortical areas V2, ${ }^{42,43}$ $\mathrm{V} 3,{ }^{43,44} \mathrm{MT},{ }^{45,46}$ and $\mathrm{MST}^{47}$ also contain populations of cells that are both directionally selective and sensitive to binocular disparity.

It is not yet possible to localise the VEP with confidence to a particular cortical area, but our derivations would favour striate or first-tier extrastriate areas. A first attempt at localising the motion VEP asymmetry was made utilising an animal model of interrupted development. In this study, the animal was raised with alternating monocular exposure during the first 16 weeks of life, achieved by means of an opaque contact lens that was alternated between the two eyes on a daily basis. The animal failed to develop stereopsis and had asymmetric MOKN at the time the deprivation period ended. The animal also developed strabismus, which was present at the time of the recording at 1 year of age. The results of a depth recording in area $\mathrm{V} 1$ are shown in Fig. 7. Local field potentials were recorded with a bipolar microelectrode pair (tip separation of $300 \mu \mathrm{m}$ ) that restricted the recording to area V1. The local field potential contained significant $F_{1}$ components that were $180 \mathrm{deg}$ out of phase in the two eyes - the characteristic response pattern found in the surface VEP of normal neonates and infantile esotropia patients.*

*The recording site was marked with an electrolytic lesion and the pattern of scarring indicated a site in upper layer 4. Direction-selective cells are concentrated in the upper layer $4\left(4 \mathrm{~A}, 4 \mathrm{~B}\right.$ and $\left.4 \mathrm{C}_{\mathrm{alpha}}\right)$ and in layer 6 of macaque V1. ${ }^{48}$
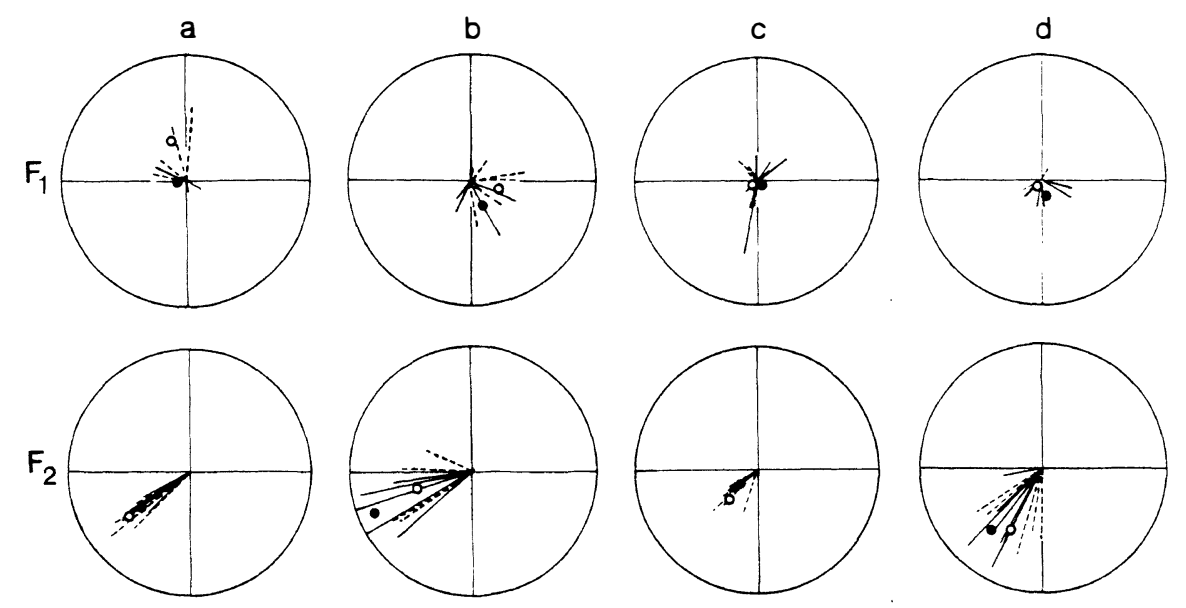

Fig. 6. Stable recovery of symmetric motion processing after surgery. Motion VEP records from 4 observers with a history of infantile esotropia who were recorded from retrospectively at $6 \mathrm{~Hz}, 1 \mathrm{c} /$ deg between 3.8 and 8.5 years after they initially achieved stable alignment to within 10 prism dioptres. The upper panels plot $\mathrm{F}_{1}$ amplitude and phase in polar format and the lower panels plot $\mathrm{F}_{2}$ amplitude and phase. In each case the response is dominated by the $\mathrm{F}_{2}$ components and the relative proportion of the $\mathrm{F}_{1}$ component of the response is within the normal range. (Reprinted with permission from Norcia et al. ${ }^{37}$ ) 
It is not clear at present whether direction asymmetries exist in other cortical areas beyond striate cortex, or whether there is more than one cortical or subcortical mechanism involved in the full range of perceptual and oculomotor asymmetries. However area V1 projects both to extrastriate area and subcortically ${ }^{49}$ and an asymmetry at this level might be expected to propagate both to higher and lower levels. On the other hand, rather than having a single source (V1) which defines the symmetry of motion processing for all other areas, there may be

Asymmetric Component (F1) AMO monkey: $10 \mathrm{~Hz}, 1 \mathrm{c} / \mathrm{deg} ; \mathrm{V} 1$ depth electrode

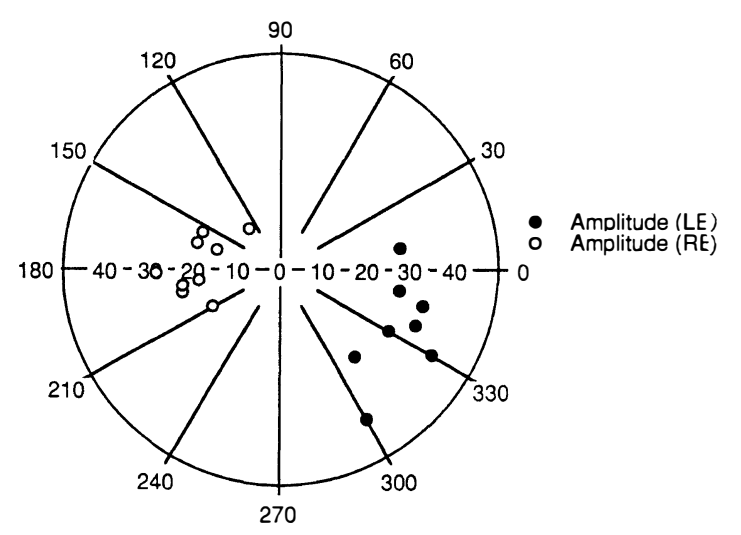

Symmetric Component (F2) AMO monkey $10 \mathrm{~Hz}, 1 \mathrm{c} /$ deg; $\mathrm{V} 1$ depth electrode

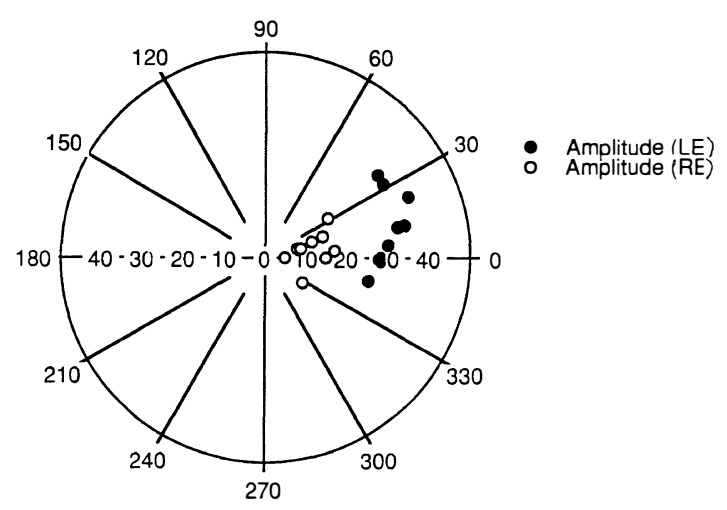

Fig. 7. Local field-potential recording from area V1 of visually deprived macaque showing characteristic monocular response asymmetry. The animal had been raised with alternate-day monocular exposure from birth to 16 weeks of age. Behavioural testing during this period indicated that the animal had normal grating acuity in each eye, no stereopsis and a monocular OKN asymmetry. The animal also had a monocular motion VEP asymmetry recorded with surface electrodes. By the end of the deprivation period, the animal had developed strabismus which was maintained until the time of the recording at 1 year of age. The upper panel shows the individual 10 second responses at $\mathrm{F}_{1}$ for the left and right eyes recorded at $10 \mathrm{~Hz}, 3 \mathrm{c} / \mathrm{deg}$. The $\mathrm{F}_{1}$ phase was 180 deg out of phase between the two eyes. The lower panels plot the $\mathrm{F}_{2}$ components from each eye. multiple sites at which developmental motion asymmetries arise through independent mechanisms. Early interruptions in binocularity may affect such sites to the extent to which they are within their critical periods of development. If each putative subsystem had an early developmental sequence, different functions could appear to be correlated when in fact they arise from separate substrates. The truth may, in fact, lie in a mixture of semiautonomous but interacting cortical and subcortical mechanisms.

Research supported by NIH EY06579, and The SmithKettlewell Eye Research Foundation. The MOKN data were collected with Donal Brosnahan and the monkey physiology was done with Takuji Kasamatsu and James Wilson.

Key words: Visual development, Motion perception, Direction selectivity, Binocular vision, Visual evoked potentials (VEPs).

\section{REFERENCES}

1. Costenbader F. Infantile estropia. Trans Am Ophthalmol Soc 1961;59:397-429.

2. Ciancia AO. La esotropia con limitacion bilateral de la abduccion en el lacante. Arch Oftalmol Buenos Aires 1962;36:207-11.

3. von Noorden GK. A reassessment of infantile esotropia. XLIV Edward Jackson Memorial Lecture. Am J Ophthalmol 1988;105:1-10.

4. Birch EE. Stereopsis in infants and its developmental relationship to visual acuity. In: Simons K, editor. Early visual development, normal and abnormal. New York: Oxford University Press, 1993:224-34.

5. Shimojo S. Development of interocular vision in infants. In: Simons K, editor. Early visual development, normal and abnormal. New York: Oxford University Press, 1993:201-23.

6. Day SH, Orel-Bixler DA, Norcia AM. Abnormal acuity development in infantile esotropia. Invest Ophthalmol Vis Sci 1988;29:327-9.

7. Birch EE, Stager DR. Monocular acuity and stereopsis in infantile esotropia. Invest Ophthalmol Vis Sci 1985;26:1624-30.

8. Schiavi C, Chiesi C, Campos E. Visual acuity maturation is negatively affected by alternating essential esotropia. In: Kaufmann $\mathrm{H}$, editor. Transactions of the 19th Meeting of the European Strabismological Association, 1991:281-4.

9. Tychsen L, Lisberger SG. Maldevelopment of visual motion processing in humans who had strabismus with onset in infancy. J Neurosci 1986;6:2495-508.

10. Schor CM, Levi-DM. Disturbances of small-field horizontal and vertical optokinetic nystagmus in amblyopia. Invest Ophthalmol Vis Sci 1980;19:668-83.

11. Mein J. The asymmetric optokinetic response. $\mathrm{Br}$ Orthoptic J 1983;40:1-4.

12. Kommerrell G. Ocular phenomenon in infantile strabismus. In: Lennerstrand $G$, von Noorden GK, Campos EC, editors. Strabismus and amblyopia. Werner-Gren International Symposium Series. Macmillan Press, 1988:99-109.

13. Demer JL, von Noorden GK. Optokinetic asymmetry in estotropia. J Pediatr Ophthalmol Strabmismus 1988; 25:286-92.

14. Reed MJ, Steinbach MJ, Anstis SM, Gallie B, Smith D, Kraft S. The development of optokinetic nystagmus in 
strabismic and monocularly enucleated subjects. Behav Brain Res 1991;46:31-42.

15. Westall CA, Shute RH. OKN asymmetries in orthoptic patients: contributing factors and effects of treatment. Behav Brain Res 1992;49:77-84.

16. Tychsen LR, Hurtig R, Scott WE. Pursuit is impaired but the vestibulo-ocular reflex is normal in infantile esotropia. Arch Ophthalmol 1985;103:536-9.

17. Ing M, Costenbader FD, Parks MM, Albert DG. Early surgery for congenital esotropia. Am J Ophthalmol 1966;61:1419-27.

18. Parks MM. Congenital esotropia with a bifixation result: report of a case. Doc Ophthalmol 1984;58: 109-14.

19. Archer S, Helveston EM, Miller K, Ellis FD. Stereopsis in normal infants and infants with congenital esotropia. Am J Ophthalmol 1986;101:591-6.

20. Rogers GL, Bremer DL, Leguire LE, Fellows RR. Clinical assessment of visual function in the young child: a prospective study of binocular vision. J Pediatric Ophthalmol Strabismus 1986;23:233-5.

21. Mohindra I, Zwaan J, Held R, Brill S, Zwaan F. Development of acuity and stereopsis in infants with esotropia. Ophthalmology 1985;92:691-7.

22. Birch EE, Stager DR, Berry P, Everett ME. Prospective assessment of acuity and stereopsis in amblyopic infantile esotropes following early surgery. Invest Ophthalmol Vis Sci 1990;31:758-65.

23. Stager DR, Birch EE. Preferential looking acuity and stereopsis in infantile esotropia. J Pediatric Ophthalmol Strabismus 1986;26:160-5.

24. Schor CM, Wilson N, Fusaro R, McKee SP. Prediction of early onset esotropia from components of the infantile squint syndrome. Invest Ophthalmol Vis Sci (Suppl) 1995;36:645

25. Hague S, Shallo-Hoffman J, Fells P, Gresty M. Abnormal motion perception in early onset esotropia. In: Lennerstrand $\mathrm{G}$, editor. Update on strabismus and pediatric ophthalmology. Boca Raton: CRC Press, 1994:106-9.

26. Hartmann EE, Succop A, Buck SL, Weiss AH, Teller DY. Quantification of monocular optokinetic nystagmus asymmetries and motion perception with motionnulling techniques. J Opt Soc Am A 1993;10:1835-40.

27. Wang A-H, Norcia AM, Jampolsky A. Reversing grating as a simple clinical method to test the symmetry of motion perception and potential binocularity. Invest Ophthalmol Vis Sci (Suppl) 1992;33:1340.

28. Norcia AM, Garcia H, Humphry R, Holmes A, Hamer RD, Orel-Bixler D. Anomalous motion VEPs in infants and in infantile esotropia. Invest Ophthalmol Vis Sci 1991;32:436-9.

29. Kommerrell G, Ulrich D, Gilles G, Bach M. Asymmetry of motion VEP in infantile strabismus and in central vestibular nystagmus. In: Fuchs AF, Brandt T, Buttner U, Zee DS, editors. Contemporary ocular motor and vestibular research: a tribute to David A. Robinson. Thieme: Stuttgart, 1994:394-7.

30. Norcia AM, Hamer RD, Orel-Bixler D. Temporal tuning of the motion VEP in infants. Invest Ophthalmol Vis Sci (Suppl) 1990;31:10.

31. Jampolsky A, Norcia AM, Hamer RD. Preoperative alternate occlusion decreases motion processing abnormalities in infantile esotropia. J Pediatr Ophthalmol Strabismus 1994;31:6-17.
32. Atkinson J. Development of optokinetic nystagmus in the human infant and monkey infant. In: Freeman RD, editor. Developmental neurobiology of vision. New York: Plenum, 1979:277-87.

33. Naegele JR, Held R. The postnatal development of monocular optokinetic nystagmus in infants. Vision Res 1982;22:341-6.

34. Teller DY, Succop A, Mar C. Infant eye movement asymmetries: stationary gratings elicit temporal-tonasal optokinetic nystagmus in 2-month-old infants. Vision Res 1994;34:1859-64.

35. Hubel DH, Wiesel TN. The period of susceptibility to the physiological effects of unilateral eye closure in kittens. J Physiol (Lond) 1970;206:419-36.

36. Sherman SM, Spear PD. Organization of visual pathways in normal and visually deprived cats. Physiol Rev 1982;62:738-855.

37. Norcia AM, Hamer RD, Jampolsky A, Orel-Bixler D. Plasticity of motion processing mechanisms following surgery for infantile esotropia. Vision Res 1995;35: 3279-96.

38. Hamer RD, Norcia AM, Orel-Bixler D, Hoyt CS. Motion VEPs in late-onset esotropia. Clin Vision Sci 1993;8:55-62.

39. Sokol S, Pelli E, Moskowitz A, Reese D. Pursuit eye movements in late onset esotropia. J Pediatr Ophthalmol Strabismus 1991;28:82-6.

40. Chandna A, Norcia AM, Peterzell DH. VEP correlates of direction-specific binocular mechanisms. Invest Ophthalmol Vis Sci (Suppl) 1993;34:1054.

41. Poggio GF, Talbot WH. Mechanisms of static and dynamic stereopsis in foveal cortex of the rhesus monkey. J Physiol (Lond) 1981;315:469-92.

42. Burkhalter A, Van Essen DC. Processing of color, form and disparity information in areas VP and V2 of ventral extrastriate cortex in the macaque monkey. J Neurosci 1986;6:2327-51.

43. Poggio GF, Gonzalez F, Krause F. Stereoscopic mechanisms in monkey visual cortex: binocular correlation and disparity selectivity. J Neurosci 1988; 8:4531-50.

44. Felleman DF, Van Essen DC. Receptive field properties of neurons in area V3 of macaque extrastriate cortex. J Neurophysiol 1987;57:889-920.

45. Maunsell JHR, Van Essen DC. Functional properties of neurons in middle temporal visual area of the macaque monkey. I. Selectivity for stimulus direction, speed and orientation. J Neurophysiol 1983; 49:1127-47.

46. Maunsell JHR, Van Essen DC. Functional properties of neurons in middle temporal visual area of the macaque monkey. II. Binocular interactions and sensitivity to disparity. J Neurophysiol 1983;49: $1148-66$

47. Roy J-P, Komatsu H, Wurtz RH. Disparity sensitive neurons in monkey extrastriate area MST. J Neurosci 1992;17:2478-92.

48. Hawken MJ, Parker AJ, Lund JS. Laminar organization and contrast sensitivity of direction-selective cells in the striate cortex of the Old World monkey. J Neurosci 1988;8:3541-8.

49. Lund JS. Anatomical organization of macaque monkey striate visual cortex. Annu Rev Neurosci 1988;11: 253-88. 